\title{
Respiratory Viruses and Torque Teno Virus in Adults with Acute Respiratory Infections
}

\author{
Afiono Agung Prasetyo ${ }^{\mathrm{a}-\mathrm{c}}$ Martinus Nuherwan Desyardi ${ }^{\mathrm{c}}$ Jimmy Tanamas $^{\mathrm{c}}$ \\ Suradi $^{d}$ Reviono $^{a, d}$ Harsini $^{a, e}$ Seiji Kageyama ${ }^{f}$ Hiroki Chikumi $^{9}$ \\ Eiji Shimizug \\ ${ }^{a}$ A-IGIC Research Group, ${ }^{b}$ Center of Biotechnology and Biodiversity Research and Development, and Departments \\ of ${ }^{\mathrm{C}}$ Microbiology and ${ }^{\mathrm{d}}$ Pulmonology, Faculty of Medicine, Sebelas Maret University, and ${ }^{\mathrm{e}}$ Department of \\ Pulmonology, Dr. Moewardi General Hospital, Surakarta, Indonesia; ${ }^{\circ}$ Division of Virology, Department of \\ Microbiology and Immunology, and ${ }^{9}$ Division of Medical Oncology and Molecular Respirology, Department of \\ Multidisciplinary Internal Medicine, Faculty of Medicine, Tottori University, Yonago, Japan
}

\section{Key Words}

Respiratory virus · Adults · Torque teno virus

\begin{abstract}
Objective: To define the molecular epidemiology of respiratory viral infections in adult patients. Methods: Nasal and throat swabs were collected from all adult patients with influenza-like illness (ILI), acute respiratory infection (ARI), or severe ARI (SARI) admitted to a tertiary hospital in Surakarta, Indonesia, between March 2010 and April 2011 and analyzed for 19 respiratory viruses and for torque teno virus (TTV) and human gyrovirus (HGyV). Results: Respiratory viruses were detected in $61.3 \%$ of the subjects, most of whom had ARI $(90.8 \%$, OR $=11.39)$, were hospitalized $(96.9 \%, \mathrm{OR}=22.31)$, had asthma exacerbation $(90.9 \%, O R=8.67)$, and/or had pneumonia $(80 \%, O R=4.0)$. Human rhinovirus (HRV) A43 predominated. Influenza A H3N2, human metapneumovirus (HMPV) subtypes $A 1$ and $A 2$, the influenza $B$ virus, human adenovirus $B$, and human coronavirus OC43 were also detected. All respiratory viruses were detected in the transition month between the rainy and dry seasons. No mixed respiratory virus infection was found. Coinfections of the influenza
\end{abstract}

A H3N2 virus with TTV, HMPV with TTV, HRV with TTV, and human parainfluenza virus-3 with TTV were found in 4.7, 2.8, 19.8 , and $0.9 \%$ of the samples, respectively. Conclusions: This study highlights the need to perform routine detection of respiratory viruses in adults hospitalized with ARI, asthma exacerbation, and/or pneumonia.

๑) 2015 S. Karger AG, Basel

\section{Introduction}

Adequate molecular epidemiology databases of infectious agents are important for infection prevention and treatment programs. However, an adequate database of that type, particularly one that includes the respiratory viruses, is not available in Indonesia, a developing country located in Southeast Asia with a tropical climate and a large population (the fourth most populous country; http:// www.indonesia.go.id/en/indonesia-glance/geographyindonesia). There is a lack of information concerning both the prevalence of respiratory virus infections and the viral genotypes circulating throughout Indonesia. The absence of this information is a barrier to the development of ap-

\section{KARGER 125}

(c) 2015 S. Karger AG, Base

0300-5526/15/0581-0057\$39.50/0

E-Mail karger@karger.com

www.karger.com/int
Afiono Agung Prasetyo

Department of Microbiology, Faculty of Medicine

Sebelas Maret University

Jl. Ir. Sutami No. 36A, Surakarta 57126 (Indonesia)

E-Mail afie.agp.la@gmail.com 
propriate public health interventions, including immunization policies and health protection measures. Respiratory virus incidence and prevalence data throughout Indonesia are also very limited and have not been well documented. Only a few reports are available [1-6] that demonstrate the presence of influenza viruses in patient populations randomly selected from various studies. The presentation of respiratory syncytial virus (RSV) has been reported in children [7-10] but not in adults. There is no information about the presentation of other respiratory viruses, including their seasonal epidemic patterns and their association with specific clinical findings. Prevalence information is also required to direct approaches for securing appropriate clinical services for infected patients. Moreover, there are few data about respiratory viral infections in adults with acute respiratory infections (ARI) in tropical climates, especially in Southeast Asia, because most studies have been performed in children. The prevalence, clinical profile, and epidemiology of respiratory viruses in adults are different from those in young people [11]. Additionally, the relationship between the geographical distribution, season, and respiratory virus species is not fully understood in adults. Consequently, there is a clear need to further study the prevalence of respiratory viruses in adults with ARI. Based on these conditions, a cross-sectional study of adults with influenza-like illness (ILI), ARI, or severe ARI (SARI) was performed at the Dr. Moewardi General Hospital, a tertiary hospital in Surakarta, Central Java, Indonesia, to determine the prevalence of a select group of human respiratory viruses, including the influenza A virus, the influenza A $\mathrm{H} 1$ virus, the influenza $A \quad H 3$ virus, the influenza $A$ H5 virus, the influenza $B$ virus, human parainfluenza virus (HPIV)-1, HPIV-2, HPIV-3, HPIV-4, RSV A, RSV B, human rhinovirus (HRV), enterovirus (EV), human coronavirus ( $\mathrm{HCoV})-\mathrm{OC} 43, \mathrm{HCoV}-$ 229E, severe acute respiratory syndrome coronavirus (SARS-CoV), human metapneumovirus (HMPV), human bocavirus (HBoV), and adenovirus. This study aimed to describe the viral genotypes, evaluate the epidemic seasonality, and determine whether specific characteristics were associated with these infections. The clinical presentation and coinfection with torque teno virus (TTV) and human gyrovirus (HGyV) were also investigated.

\section{Materials and Methods}

\section{Study Population}

This study was performed from March, 2010 through April, 2011 at the Dr. Moewardi General Hospital in Surakarta, Central Java, Indonesia, the most densely populated city in Central Java and the eighth most densely populated city in Indonesia [12]. All adult patients admitted to the Department of Pulmonology of the Dr. Moewardi General Hospital with ILI, ARI, or SARI, according to the World Health Organization (WHO) case definition [13], were enrolled into this study. Patients with underlying diseases (HIV/AIDS, diabetes mellitus, tuberculosis, alcoholism, chronic kidney disease, chronic liver disease, asplenia, leukopenia, cavitary infiltrates, pleural effusion, and sepsis) were excluded. Approval was obtained from the institutional ethical committee review boards of the Faculty of Medicine of Sebelas Maret University and the Dr. Moewardi General Hospital. Written informed consent was obtained from all individuals participating in this study. Upper respiratory (nasal and throat swabs) specimens were collected from each participant after informed consent had been obtained. The collected specimens were placed into viral transport media (BD Universal Viral Transport, Sparks, Md., USA) and kept at $4^{\circ}$ during transportation. The clinical data were obtained from the patient medical records. All procedures were conducted according to the principles of the Declaration of Helsinki.

\section{Nucleic Acid Extraction and Molecular Detection of Human}

Respiratory Viruses

Both viral RNA and DNA were extracted on the same day of collection using a PureLink Viral RNA/DNA Kit (Invitrogen, Carlsbad, Calif., USA) according to the manufacturer's instructions. The nucleic acids were then aliquoted, and one aliquot was reverse-transcribed using a Superscript III First-Strand cDNA Synthesis SuperMix Kit with random hexamers (Invitrogen). All DNA and cDNA were used immediately for nested multiplex PCR for 19 respiratory viruses as described previously [14]. Briefly, each nested multiplex PCR assay detected several pathogens: group 1 contained influenza A- and B-specific primers and subtype $\mathrm{H} 1 \mathrm{~N} 1$-, $\mathrm{H} 3 \mathrm{~N} 2$-, and $\mathrm{H} 5 \mathrm{~N} 1$-specific primers; group 2 contained primers for the parainfluenza viruses (PIV-1, PIV-2, PIV-3, PIV-4a, and PIV4b); group 3 contained primers for RSV A, RSV B, HRV, and EV; group 4 contained primers for $\mathrm{HCoV}-\mathrm{OC} 43$, HCoV-229E, SARS$\mathrm{CoV}$, and $\mathrm{HMPV}$, and group 5 contained primers for $\mathrm{HBoV}$, adenovirus 1, adenovirus 2, adenovirus 3, Mycoplasma pneumoniae, and Chlamydophila pneumoniae. Molecular detection was performed by PCR using a AmpliTaq Gold ${ }^{\circledR} 360$ DNA Polymerase Kit (Invitrogen). Internal amplification controls were included in each molecular assay to exclude false-negative results. The corresponding positive controls and one negative control (sterile water) sample were included for each group simultaneously. To prevent PCR contamination, the reagent preparation, sample processing, and nested PCR assays were performed in rooms separate from where the amplified products were analyzed. Aerosol-resistant pipette tips were used throughout the assays. The PCR products were subjected to electrophoresis in $2 \%$ agarose gels, stained with ethidium bromide, and visualized under ultraviolet illumination. All samples were tested at least twice.

\section{Molecular Detection of TTV and HGyV}

The pathological role of TTV in respiratory diseases remains poorly understood; therefore, all respiratory samples were also tested for TTV DNA by nested PCR amplification of a conserved region of ORF2, as described previously [15]. Internal amplification controls were included in each molecular assay to exclude false-negative results. The corresponding positive controls and one negative control (sterile water) sample were included for each 
group simultaneously. PCR specificity was confirmed by sequencing of the amplicons. All samples were tested at least twice.

In 2011, a novel virus resembling chicken anemia virus (CAV) was reported and named HGyV [16]. The epidemiology, biologic properties, and pathogenic potential of $\mathrm{HGyV}$ remain poorly understood; therefore, all samples were also tested for HGyV DNA using a previously published nested PCR method [17]. Internal amplification controls were included in each molecular assay to exclude false-negative results. The corresponding positive controls and one negative control (sterile water) sample were included for each group simultaneously. PCR specificity was confirmed by sequencing the amplicons. All samples were tested at least twice.

\section{Determination of Nucleotide Sequences and Phylogenetic}

Analyses

The PCR products were purified from agarose gels, and nucleotide sequencing was performed in both orientations using the inner primers from the nested PCR assays. The sequences were then submitted to the BLAST program to check their similarity to related strains deposited in GenBank/EMBL/DDBJ. The reference strains with the highest homology score to each analyzed strain were retrieved from the GenBank/EMBL/DDJB databases and aligned with the test sequences. All sequences of the selected respiratory viruses that were isolated in Indonesia and deposited in GenBank were also included in the alignment analysis for each tested sequence. However, with respect to the respiratory viruses studied here, only 4 Influenza A HA gene sequences from Indonesia that were deposited in GenBank could be found. The frequency of nucleotide substitution at each base was estimated using the Kimura 2-parameter method. A phylogenetic tree was constructed via the neighbor-joining method, and its reliability was estimated by 1,000 bootstrap replicates. The phylogenetic tree was constructed using the MEGA version 5 software package [18].

\section{Statistical Analysis}

Statistical analyses were performed using SPSS version 20 software (SPSS, Chicago, Ill., USA), and 95\% CI were used for all data analyses. OR were calculated according to a previously published method [19].

Accession Numbers

The sequences described in this article have been deposited in GenBank/EMBL/DDBJ under accession numbers KC513508 to KC513572.

\section{Results}

\section{Characteristics and Clinical Features}

In total, 685 patients were admitted to the Department of Pulmonology of the Dr. Moewardi General Hospital in Surakarta, Indonesia, during the study period. Based on the WHO case definition of ILI, ARI, and SARI and the exclusion criteria, only 106 patients (63 men and 43 women) met the criteria; therefore, only 106 patients were enrolled into the present study.

Respiratory Viruses and TTV in Adults with ARI
The mean age of the study patients was 56.1 years (range 18-96). The mean BMI of the patients was 20.2 (range 12.9-31.1). Elevated respiratory rates of more than 20 breaths/min were found in $70.8 \%(75 / 106)$ of patients. Fever was found in $71.7 \%(76 / 106)$ of patients. Crackles were found in $44.3 \%(47 / 106)$ of patients, and wheezing was found in $38.7 \%$ (41/106) of patients. ILI, ARI, and SARI were initially diagnosed in $26.4 \%$ (28/106), $73.6 \%$ (78/106), and $0 \%(0 / 106)$ of patients, respectively. Based on the clinical and radiological examinations [20], pneumonia was found in $37.7 \%$ (40/106) of patients. Exacerbations of asthma, chronic obstructive pulmonary disease (COPD), and bronchiectasis were found in $20.8 \%(22 / 106), 13.2 \%$ $(14 / 106)$, and $2.8 \%$ (3/106) of patients, respectively. Nineteen (17.9\%) patients had hypertension. Forty-eight (45.3\%) patients had anemia, and 40 (37.7\%) patients had leukocytosis. After careful medical examination of all patients, 19 patients (17.9\%) were treated as outpatients, and 87 patients $(82.1 \%)$ were hospitalized for a mean duration of 7.8 days (range 2-33). All patients received antibiotic therapy. One hundred three (97.2\%) patients fully recovered, whereas 3 patients died. None of the subjects enrolled into this study had ever received an influenza vaccination.

\section{Respiratory Virus Infection}

Respiratory viruses were detected in a total of 65 (61.3\%) samples (table 1), with $96.9 \%$ (63/65) from hospitalized patients $(\mathrm{OR}=22.31 ; 95 \%$ CI $4.789-103.951)$ and only $3.1 \%$ from outpatients (OR $=0.04$; 95\% CI $0.009-0.209)$. Respiratory viruses were detected in $75.6 \%$ (59/78) of patients with ARI (OR $=11.39$; 95\% CI 4.023$32.223)$, whereas only $21.4 \%(6 / 28)$ of ILI patients were positive for respiratory viruses $(\mathrm{OR}=0.09 ; 95 \% \mathrm{CI} 0.031$ 0.249). Almost all ARI patients who were positive for a respiratory virus were hospitalized $(96.7 \%, 57 / 59$; OR = 5.34 ; 95\% CI 0.821-34.783). Respiratory viruses were detected in $90.9 \%(20 / 22)$ of patients with asthma exacerbation $(\mathrm{OR}=8.67$; 95\% CI 1.904-39.448), with HRV being most frequently detected $(65 \%, 13 / 20)$, followed by influenza A H3 virus $(25 \%, 5 / 20)$, $\operatorname{HMPV}(5 \%, 1 / 20)$, and HPIV-3 $(5 \%, 1 / 20)$ (table 1$)$. No mixed respiratory virus infections were found. None of the respiratory pathogens or coinfection was associated with the severity of asthma exacerbation; however, all patients with asthma exacerbation were hospitalized. In the samples derived from patients with pneumonia, $80 \%(32 / 40)$ were found positive for respiratory viruses $(\mathrm{OR}=4.0 ; 95 \% \mathrm{CI} 1.606-9.964)$, with HRV being most frequently detected $(59.4 \%, 19 / 32)$, followed by the influenza A H3 virus $(18.8 \%, 6 / 32)$, HMPV $(18.8 \%, 6 / 32)$, and the influenza B virus $(3 \%$, 
Table 1. Clinical features of patients with ILI and ARI who were infected with a respiratory virus

\begin{tabular}{|c|c|c|c|c|c|c|c|c|}
\hline Clinical features & $\begin{array}{l}\text { Influenza A } \\
\mathrm{H} 3 \\
(\mathrm{n}=11)\end{array}$ & $\begin{array}{l}\text { Influenza B } \\
\text { virus } \\
(\mathrm{n}=1)\end{array}$ & $\begin{array}{l}\text { HMPV } \\
(n=8)\end{array}$ & $\begin{array}{l}\text { HRV } \\
(n=42)\end{array}$ & $\begin{array}{l}\text { Adenovirus } \\
(\mathrm{n}=1)\end{array}$ & $\begin{array}{l}\text { HCoV-OC43 } \\
(\mathrm{n}=1)\end{array}$ & $\begin{array}{l}\text { HPIV-3 } \\
(n=1)\end{array}$ & $\begin{array}{l}\text { TTV } \\
(\mathrm{n}=33)\end{array}$ \\
\hline \multicolumn{9}{|l|}{ Sex } \\
\hline Male $(n=63)$ & 8 & 1 & 6 & 27 & 1 & 0 & 0 & 19 \\
\hline Female $(n=43)$ & 3 & 0 & 2 & 15 & 0 & 1 & 1 & 14 \\
\hline \multicolumn{9}{|l|}{ Age (years) } \\
\hline$<20(\mathrm{n}=1)$ & 1 & 0 & 0 & 0 & 0 & 0 & 0 & 0 \\
\hline $21-30(n=9)$ & 0 & 0 & 1 & 2 & 0 & 0 & 0 & 2 \\
\hline $31-40(\mathrm{n}=7)$ & 0 & 0 & 0 & 1 & 0 & 0 & 0 & 0 \\
\hline $41-50(n=19)$ & 1 & 1 & 3 & 8 & 0 & 1 & 1 & 8 \\
\hline $51-60(\mathrm{n}=27)$ & 2 & 0 & 2 & 12 & 0 & 0 & 0 & 11 \\
\hline $61-70(\mathrm{n}=30)$ & 7 & 0 & 2 & 11 & 0 & 0 & 0 & 8 \\
\hline $71-80(\mathrm{n}=8)$ & 0 & 0 & 0 & 5 & 0 & 0 & 0 & 4 \\
\hline$>81(\mathrm{n}=5)$ & 0 & 0 & 0 & 3 & 1 & 0 & 0 & 0 \\
\hline \multicolumn{9}{|l|}{ Initial diagnosis } \\
\hline ILI $(n=28)$ & 1 & 0 & 0 & 5 & 0 & 0 & 0 & 5 \\
\hline $\operatorname{ARI}(\mathrm{n}=78)$ & 10 & 1 & 8 & 37 & 1 & 1 & 1 & 28 \\
\hline \multicolumn{9}{|l|}{ Signs of pneumonia } \\
\hline No signs of pneumonia $(n=66)$ & 5 & 0 & 2 & 23 & 1 & 1 & 1 & 20 \\
\hline Pneumonia $(\mathrm{n}=40)$ & 6 & 1 & 6 & 19 & 0 & 0 & 0 & 13 \\
\hline \multicolumn{9}{|l|}{ Exacerbations } \\
\hline No exacerbation $(n=67)$ & 4 & 1 & 6 & 18 & 0 & 1 & 0 & 13 \\
\hline Asthma $(\mathrm{n}=22)$ & 5 & 0 & 1 & 13 & 0 & 0 & 1 & 10 \\
\hline $\operatorname{COPD}(\mathrm{n}=14)$ & 2 & 0 & 1 & 10 & 1 & 0 & 0 & 10 \\
\hline Bronchiectasis $(\mathrm{n}=3)$ & 0 & 0 & 0 & 1 & 0 & 0 & 0 & 0 \\
\hline \multicolumn{9}{|l|}{ Hospitalization status } \\
\hline Outpatients $(n=19)$ & 0 & 0 & 0 & 2 & 0 & 0 & 0 & 3 \\
\hline Hospitalized patients $(n=87)$ & 11 & 1 & 8 & 40 & 1 & 1 & 1 & 30 \\
\hline \multicolumn{9}{|l|}{ Hospitalization time (days) } \\
\hline $1-3(n=7)$ & 3 & 0 & 0 & 3 & 0 & 0 & 0 & 3 \\
\hline $4-7(n=39)$ & 4 & 1 & 4 & 20 & 0 & 1 & 1 & 14 \\
\hline $8-14(\mathrm{n}=28)$ & 4 & 0 & 3 & 11 & 1 & 0 & 0 & 9 \\
\hline$>15(\mathrm{n}=13)$ & 0 & 0 & 1 & 6 & 0 & 0 & 0 & 4 \\
\hline
\end{tabular}

Values are presented as numbers.

$1 / 32$ ). All pneumonia patients who were positive for a respiratory virus were hospitalized. M. pneumoniae and C. pneumoniae were not found in any sample. Unless otherwise stated, no significant associations were detected between the presence of respiratory viruses and the clinical features of the patients.

Figure 1 illustrates the seasonality patterns for the respiratory viruses detected in patients throughout the study period. HRV was detected almost every month and peaked during the 2010 dry season (August to October) and in the transition months from the dry season to the rainy season (November to December 2010). The influenza A viruses, HMPV, adenoviruses, HPIV-3, and $\mathrm{HCoV}-\mathrm{OC} 43$ were primarily detected during the transi- tion months from the rainy season to the dry season (March to April) (fig. 1).

Influenza A H3N2 was detected in 3.6\% (1/28) of ILI samples (OR $=0.25 ; 95 \%$ CI $0.031-2.064)$ and $12.8 \%$ $(10 / 78)$ of ARI samples $(\mathrm{OR}=3.97$; 95\% CI $0.485-$ 32.537), all of which were from hospitalized patients (table 1). Influenza A H3N2 was detected in 5 samples taken from patients with asthma exacerbation (OR = 3.82; 95\% CI 1.045-13.996). Two out of 14 (14.3\%) patients with COPD exacerbation were positive for the influenza A H3N2 virus (OR $=1.54$; 95\% CI 0.296-7.983). Influenza A H3N2 was detected in 15\% (6/40) of samples taken from patients with pneumonia $(\mathrm{OR}=2.15 ; 95 \% \mathrm{CI}$ 0.611-7.581).
60

Intervirology 2015;58:57-68 DOI: $10.1159 / 000369211$
Prasetyo et al. 
Fig. 1. Seasonality patterns for the respiratory viruses detected in patients with ARI who were admitted to the Department of Pulmonology of the Dr. Moewardi General Hospital in Surakarta, Indonesia, from March, 2010 through April, 2011. In 2010-2011, June to November was the dry season while December to May was the rainy season. Jan. = January; Feb. = February; Mar. = March; Apr. = April; Jun. = June; Jul. = July; Aug. = August; Sep. $=$ September; Oct. $=$ October; Nov. $=$ November; Dec. $=$ December.

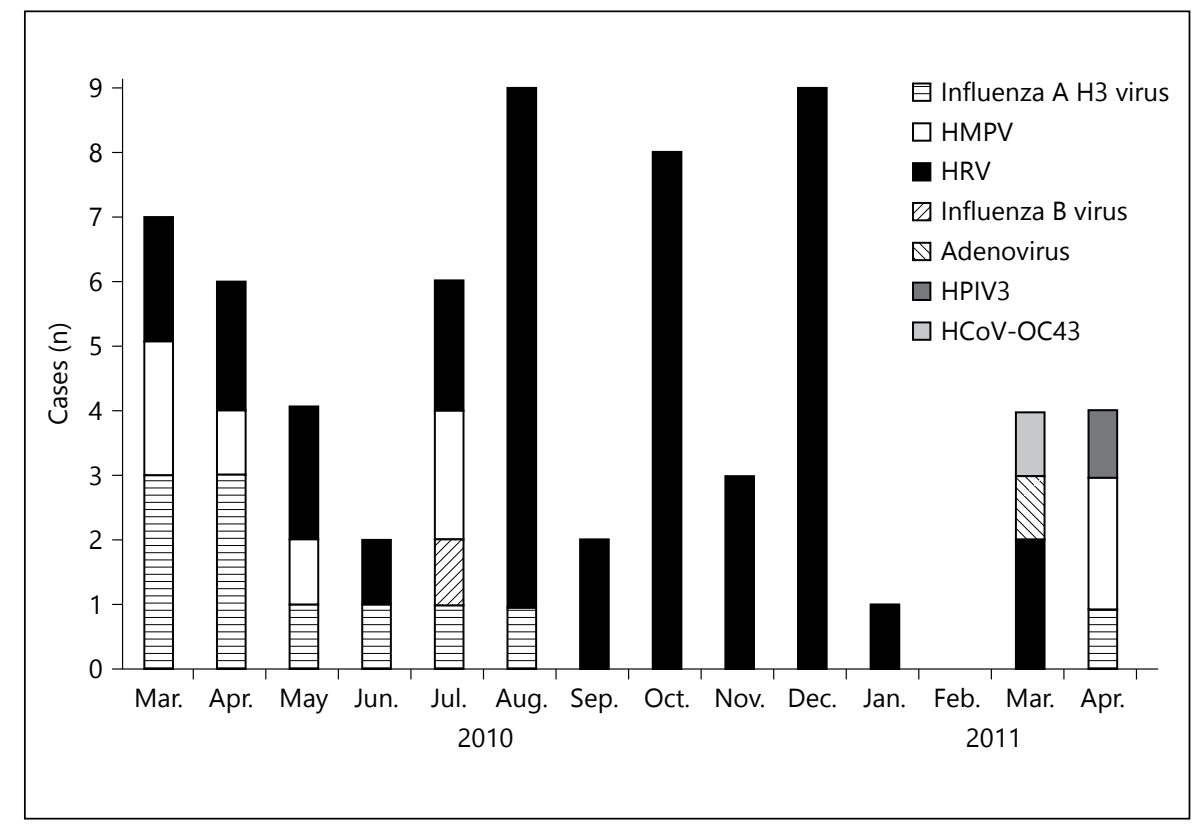

A 260-bp fragment of the influenza A HA gene [corresponding to nucleotide position (nt) 342-601 in the $H A$ gene from A/Georgia/3058/2012(H3N2), GenBank accession No. CY130194] could be amplified by nested RT-PCR from 11 study samples. The sequences from 5 of these samples [A/Surakarta/1/2010(H3N2), A/ Surakarta/2/2010(H3N2), A/Surakarta/5/2010(H3N2), A/Surakarta/6/2010(H3N2), and A/Surakarta/11/2011 (H3N2)] shared $99.2-100 \%$ nucleotide homology with A/Singapore/H2010.471C/2010(H3N2). Sequences from 2 influenza A virus isolates [A/Surakarta/4/2010 (H3N2) and A/Surakarta/7/2010(H3N2)] clustered together in the phylogenetic tree and shared $100 \%$ nucleotide homology with A/Guangdong/SZ2171/2009 (H3N2). Sequences from 2 additional influenza A virus isolates [A/Surakarta/3/2010(H3N2) and A/Surakarta/8/2010(H3N2)] shared 99.2\% nucleotide homology with A/Georgia/3058/2012(H3N2). Sequences from the final 2 influenza A virus isolates [A/Surakarta/9/2010 (H3N2) and A/Surakarta/10/2010(H3N2)] shared 99.2100\% nucleotide homology with A/Guangdong/SZ4385/ 2008(H3N2). All influenza A H3N2 viruses shared 98.5-99.2\% nucleotide homology with 2 influenza A $\mathrm{H} 3 \mathrm{~N} 2$ viruses isolated previously in Surabaya, Indonesia [A/Surabaya/40/2010(H3N2) and A/Surabaya/57/ 2010(H3N2)]; however, they shared only $85.4-87.7 \%$ nucleotide homology with influenza A H3N2 viruses isolated previously from Indonesia in 1991-1992
[A/Indonesia/3946/92(H3N2) and A/Indonesia/3109/ 91(H3N2)] (fig. 2).

The influenza B virus was detected in one sample derived from a hospitalized patient with ARI and pneumonia (table 1). Based on the sequence obtained from 516 nucleotides from the nucleoprotein (NP) gene (corresponding to nt 873-1388 in the NP gene from B/Malaysia/1781325/ 2007, GenBank accession No. CY119909), the influenza B virus isolate shared $98.6 \%$ homology with $\mathrm{B} /$ Malaysia/ $1781325 / 2007$. At present, this sequence represents the first and only molecular data in GenBank for an influenza $B$ virus isolated in Indonesia.

HMPV was detected only in samples derived from hospitalized patients with ARI $(\mathrm{n}=8)$. One HMPV-positive sample was derived from a patient with asthma exacerbation, and 1 was derived from a patient with COPD exacerbation; the remaining $6 \mathrm{HMPV}$-positive samples were not associated with any respiratory exacerbation (table 1). Six samples $(15 \%, 6 / 40)$ derived from patients with pneumonia were positive for HMPV $(\mathrm{OR}=5.65 ; 95 \% \mathrm{CI}$ 1.081-29.508).

Based on the sequence from 432 nucleotides from the matrix protein $(M)$ region (corresponding to nt 22792710 in HMPV-gz01, GenBank accession No. GQ153651), 4 HMPV isolates (IDSKAHMPV-3, IDSKAHMPV-4, IDSKAHMPV-6, and IDSKAHMPV-7) were clustered together with TN96-12, an isolate from the USA. Two HMPV isolates (IDSKAHMPV-1 and IDSKAHMPV-2) 
Fig. 2. Phylogenetic analysis of influenza $A$ isolates obtained from this study ( $\boldsymbol{\square})$ based on nucleotide sequences from the $H A$ gene. The GenBank accession numbers for the references in the phylogenetic tree are as follows: A/Georgia/3058/2012(H3N2), CY130194; A/Singapore/H2010.471C/ 2010(H3N2), JX437833; A/Guangdong/ SZ2171/2009(H3N2), CY106548; A/ Guangdong/SZ4385/2008(H3N2), CY106497; A/Surabaya/40/2010(H3N2), CY093083; A/Surabaya/57/2010(H3N2), CY093084; A/Indonesia/3946/92(H3N2), AF008694, and A/Indonesia/3109/91 (H3N2), AF008810.

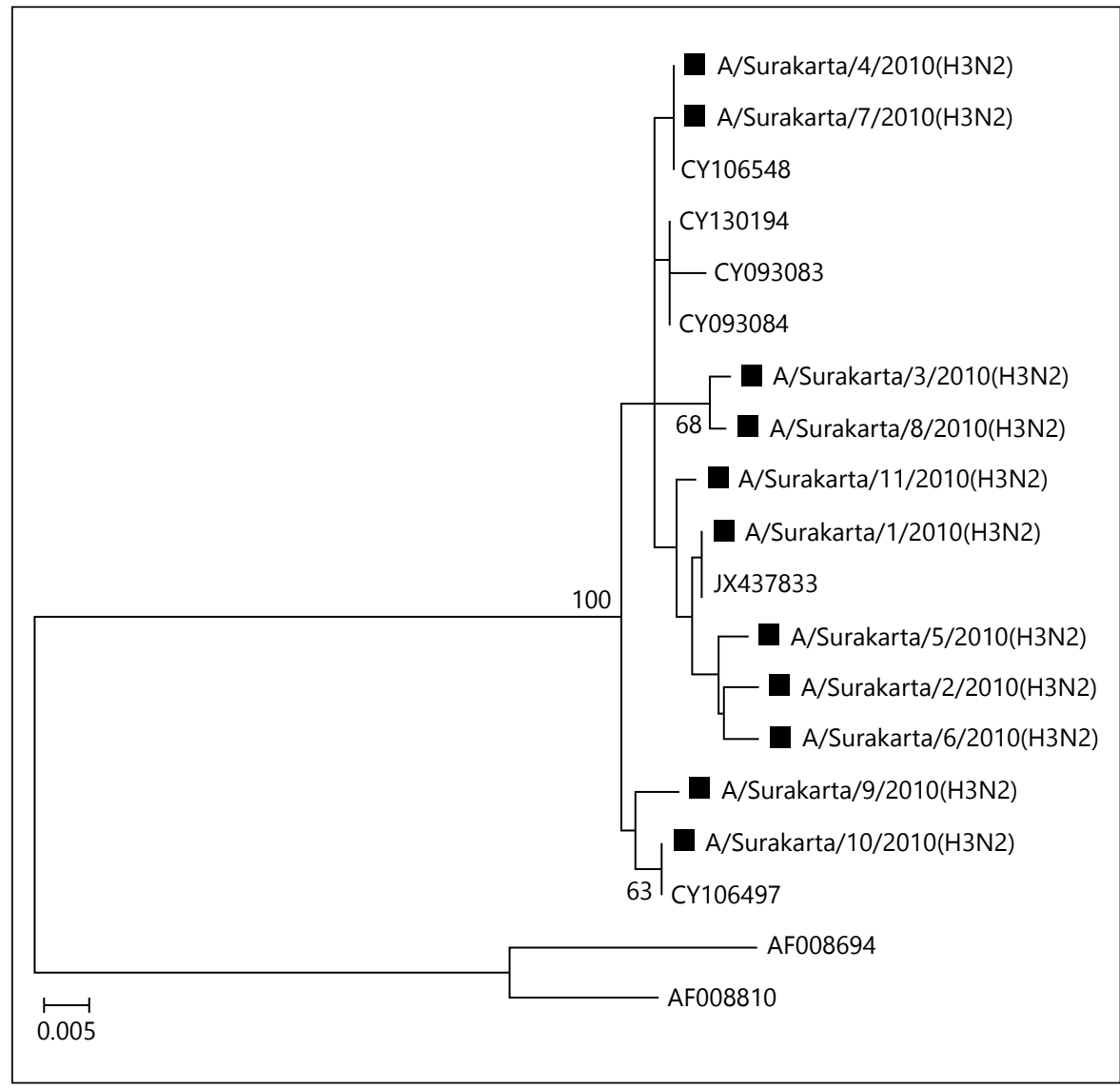

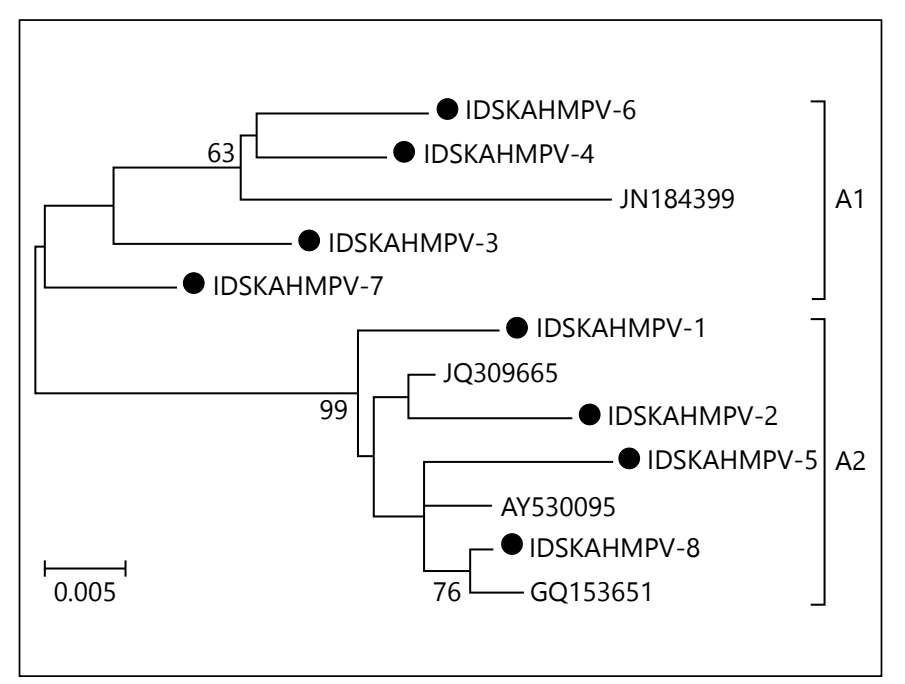

Fig. 3. Phylogenetic analysis of HMPV isolates obtained from this study ( $)$ based on nucleotide sequences from the $M$ gene. The GenBank accession numbers for the references in the phylogenetic tree are as follows: HMPV-gz01 (HMPV A2), GQ153651; JPS03240 (HMPV A2), AY530095; SIN07-NTU442 (HMPV A2), JQ309665, and TN96-12 (HMPV A1), JN184399. were closely related to SIN07-NTU442, an isolate from Singapore. IDSKAHMPV -5 shared $98.8 \%$ homology with an HMPV isolate from Japan (JPS03-240), and IDSKAHMPV-8 shared $99.8 \%$ homology with the HMPVgz01 isolate from Guangzhou, China. Two HMPV subtypes were found: A1 (4/8) and A2 (4/8) (fig. 3).

HRV was detected in $17.9 \%(5 / 28)$ of ILI samples $(\mathrm{OR}=0.24 ; 95 \%$ CI $0.083-0.698)$ and $47.4 \%$ (37/78) of ARI samples $(\mathrm{OR}=4.15$; 95\% CI 1.432-12.034). Most HRVs $(95.2 \%, 40 / 42)$ were detected in hospitalized patients (OR $=7.23$; 95\% CI 1.575-33.230). Infection with HRV was detected in $59.1 \%(13 / 22)$ of the samples taken from patients with asthma exacerbations $(\mathrm{OR}=2.74 ; 95 \%$ CI 1.047-7.166). HRV was also detected in $71.4 \%(10 / 14)$ of samples taken from patients with COPD exacerbation $(\mathrm{OR}=4.69 ; 95 \% \mathrm{CI} 1.361-16.140)$. One of the 3 patients with bronchiectasis exacerbation was positive for HRV. Of all patients with pneumonia, $47.5 \%$ (19/40) were positive for $\mathrm{HRV}(\mathrm{OR}=1.69 ; 95 \%$ CI 0.759-3.768) (table 1).

HRV A RNA was successfully amplified by RT-PCR from a total of 14 study samples, and $294 \mathrm{bp}$ from each 
Fig. 4. a Phylogenetic analysis of HRV A isolates obtained from this study $(\boldsymbol{A})$ based on the 5UTR nucleotide sequences. The GenBank accession numbers for the references in the phylogenetic tree are as follows: 95-01943 (HRV A43), AF108172; HRV-A43_p1224_sR3080_2008 (HRV A43), JN815237; ATCC VR-1153 (HRV A43), FJ445131; HRV-A75_p1038_ sR149_2008 (HRV A75), JN837690, and 95-01469 (HRV A19), AF108165.

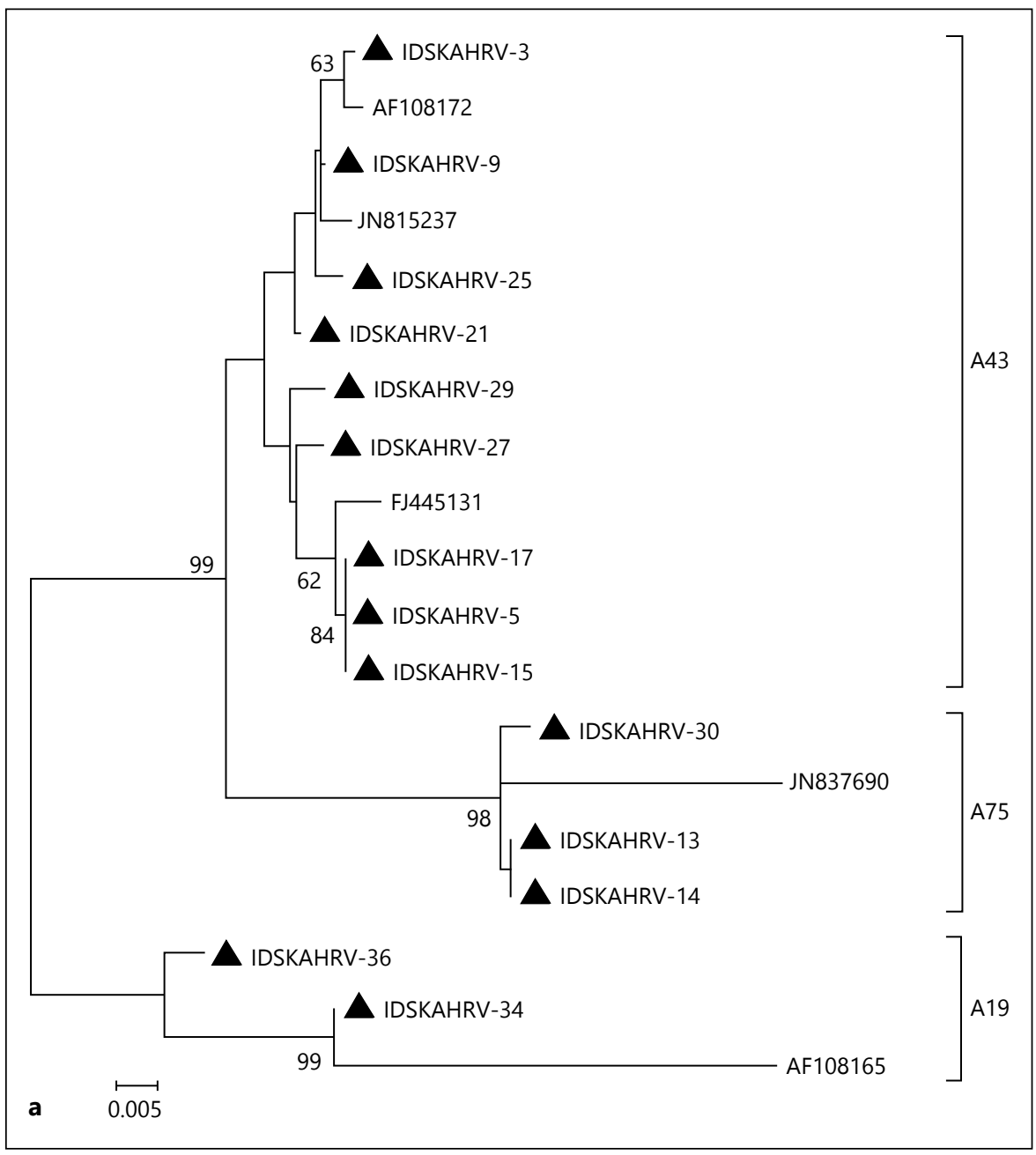

amplicon were sequenced, corresponding to the viral 5UTR region (nt 168-461 in strain ATCC VR-1153, GenBank accession No. FJ445131). The HRV genotype A43 was found in 9 subjects, genotype A75 was found in 3 subjects, and genotype A19 was found in 2 subjects (fig. 4a). HRV B RNA was successfully amplified by RTPCR from a total of 27 study samples, and $291 \mathrm{bp}$ from each amplicon were sequenced, corresponding to the viral 5UTR region (nt 186-476 in strain ATCC VR-1182, GenBank accession No. FJ445153). The HRV genotype B3 was found in 7 subjects, genotype B37 was found in 3 subjects, genotype B6 was found in 7 subjects, genotype B14 was found in 4 subjects, genotype B72 was found in 5 subjects, and genotype B92 was found in 1 subject (fig. 4b). Only one HRV C (accession No. KC513545) was detected, and it shared $98 \%$ homology with the HRV C strain PHL/TTa469S/2008, which was isolated from

Respiratory Viruses and TTV in Adults with ARI children with severe respiratory infections in the Philippines.

Adenovirus was detected in one sample taken from a hospitalized ARI patient with COPD exacerbation (IDSKAADV-1) (table 1). Based on a 463-bp segment of the Hexon protein gene (corresponding to nt 18537-18999 in human/CHN/BJ01/2011/55/P14H11F14, GenBank accession No. JX491639), the IDSKAADV-1 isolate shared $100 \%$ homology with a human adenovirus B isolate from China (human/CHN/BJ01/2011/55/P14H11F14).

$\mathrm{HCoV}-\mathrm{OC} 43$ was detected in one sample taken from a hospitalized patient with ARI (table 1). Based on a 636bp segment of the surface glycoprotein $S$ gene (corresponding to nt 24695-25330 in strain ATCC VR-759, GenBank accession No. AY391777), this isolate shared $100 \%$ homology with the ATCC VR-759 isolate from Belgium. 
Fig. 4. b Phylogenetic analysis of HRV B isolates obtained from this study $(\boldsymbol{\nabla})$ based on the 5UTR nucleotide sequences. The GenBank accession numbers for the references in the phylogenetic tree are as follows: (no strain name listed) (HRV B3), EU095990; (no strain name listed) (HRV B37), EU096024; BCH186 (HRV B37), GU568045; PUMCH3613 (HRV B6), FJ950922; HRV-B06_p1198_sR1308_2009 (HRV B6), JN815239; ATCC VR-486 (HRV B6), EU870478; BCH112 (HRV B6), GU568040; (no strain name listed) (HRV B14), EU096001; ATCC VR-284 (HRV B14), EU870450; HRV-B72_p1051_ sR207_2007 (HRV B72), JN798562; ATCC VR-1182 (HRV B72), FJ445153, and PUMCH5773 (HRV B92), FJ950971.

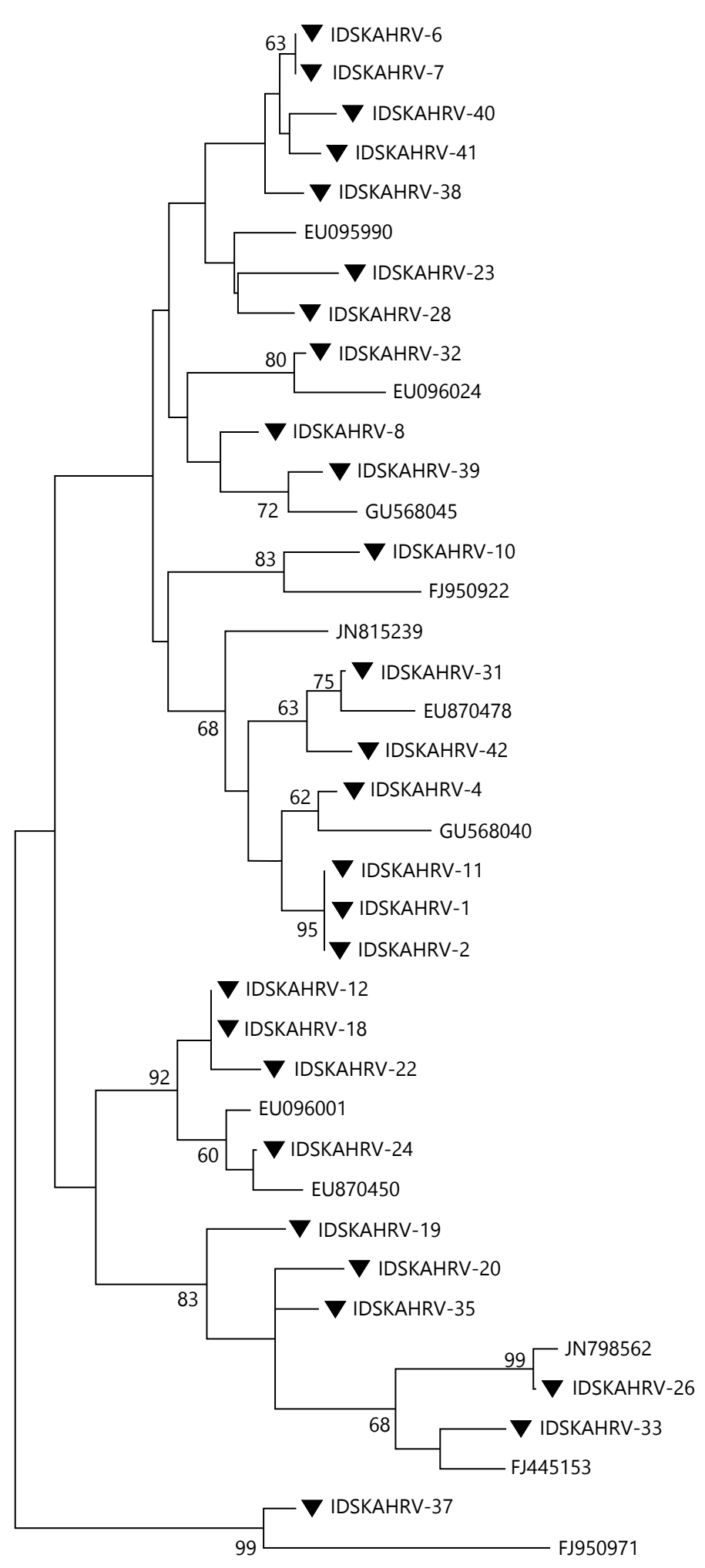


Table 2. Clinical features of patients with ILI and ARI who were coinfected with TTV and a respiratory virus

\begin{tabular}{|c|c|c|c|c|c|}
\hline Clinical features & $\begin{array}{l}\text { TTV } \\
\text { (TTV-positive) } \\
(\mathrm{n}=33)\end{array}$ & $\begin{array}{l}\text { TTV/influenza A } \\
\text { H3 virus } \\
\text { (influenza-A-H3- } \\
\text { virus-positive) } \\
(\mathrm{n}=11)\end{array}$ & $\begin{array}{l}\text { TTV/HMPV } \\
\text { (HMPV-positive) } \\
(\mathrm{n}=8)\end{array}$ & $\begin{array}{l}\text { TTV/HRV } \\
\text { (HRV-positive) } \\
(\mathrm{n}=42)\end{array}$ & $\begin{array}{l}\text { TTV/HPIV-3 } \\
\text { (HPIV-3-positive) } \\
(\mathrm{n}=1)\end{array}$ \\
\hline \multicolumn{6}{|l|}{ Initial diagnosis } \\
\hline $\operatorname{ILI}(n=28)$ & $40(2 / 5)$ & $0(0 / 1)$ & $0(0 / 0)$ & $60(3 / 5)$ & $0(0 / 0)$ \\
\hline $\operatorname{ARI}(\mathrm{n}=78)$ & $3.6(1 / 28)$ & $50(5 / 10)$ & $37.5(3 / 8)$ & $48.6(18 / 37)$ & $100(1 / 1)$ \\
\hline \multicolumn{6}{|l|}{ Exacerbations } \\
\hline No exacerbation $(n=67)$ & $23.1(3 / 13)$ & $50(2 / 4)$ & $50(3 / 6)$ & $27.8(5 / 18)$ & $0(0 / 0)$ \\
\hline Asthma $(\mathrm{n}=22)$ & $0(0 / 10)$ & $20(1 / 5)$ & $0(0 / 1)$ & $0(0 / 13)$ & $100(1 / 1)$ \\
\hline $\operatorname{COPD}(\mathrm{n}=14)$ & $0(0 / 10)$ & $100(2 / 2)$ & $0(0 / 1)$ & $80(8 / 10)$ & $0(0 / 0)$ \\
\hline Bronchiectasis $(\mathrm{n}=3)$ & $0(0 / 0)$ & $0(0 / 0)$ & $0(0 / 0)$ & $0(0 / 1)$ & $0(0 / 0)$ \\
\hline \multicolumn{6}{|l|}{ Signs of pneumonia } \\
\hline No signs of pneumonia $(n=66)$ & $15(3 / 20)$ & $40(2 / 5)$ & $50(1 / 2)$ & $56.5(13 / 23)$ & $100(1 / 1)$ \\
\hline Pneumonia $(n=40)$ & $0(0 / 13)$ & $50(3 / 6)$ & $33.3(2 / 6)$ & $42.1(8 / 19)$ & $0(0 / 0)$ \\
\hline \multicolumn{6}{|l|}{ Hospitalization status } \\
\hline Outpatients $(\mathrm{n}=19)$ & $100(3 / 3)$ & $0(0 / 0)$ & $0(0 / 0)$ & $50(1 / 2)$ & $0(0 / 0)$ \\
\hline Hospitalized patients $(n=87)$ & $0(0 / 30)$ & $45.5(5 / 11)$ & $37.5(3 / 8)$ & $50(20 / 40)$ & $100(1 / 1)$ \\
\hline \multicolumn{6}{|l|}{ Hospitalization time (days) } \\
\hline $1-3(n=7)$ & $0(0 / 3)$ & $0(2 / 3)$ & $0(0 / 0)$ & $33.3(1 / 3)$ & $0(0 / 0)$ \\
\hline $4-7(\mathrm{n}=39)$ & $0(0 / 14)$ & $0(0 / 4)$ & $50(2 / 4)$ & $55(11 / 20)$ & $100(1 / 1)$ \\
\hline $8-14(\mathrm{n}=28)$ & $0(0 / 9)$ & $75(3 / 4)$ & $0(0 / 3)$ & $54.5(6 / 11)$ & $0(0 / 0)$ \\
\hline$>15(n=13)$ & $0(0 / 4)$ & $0(0 / 0)$ & $100(1 / 1)$ & $33.3(2 / 6)$ & $0(0 / 0)$ \\
\hline
\end{tabular}

Values are presented as percents (n/total).

HPIV-3 was detected in one sample derived from a hospitalized ARI patient with asthma exacerbation (table 1). Based on a 717-bp segment of the hemagglutinin-neuraminidase $(H N)$ gene (corresponding to $\mathrm{nt}$ 7604-8320 in strain ZHYMgz01, GenBank accession No. EU326526), this isolate shared $97.4 \%$ homology with the HPIV-3 strain ZHYMgz01 from China.

\section{TTV and HGyV in Nasal and Throat Samples}

TTV DNA was detected in $31.1 \%(33 / 106)$ of the samples, with $15.2 \%(5 / 33)$ taken from patients with ILI $(\mathrm{OR}=0.09 ; 95 \% \mathrm{CI} 0.026-0.293)$ and $84.8 \%(28 / 33)$ taken from patients with ARI (OR $=2.58 ; 95 \%$ CI 0.882-7.526). Three patients with samples positive for TTV DNA were not hospitalized, whereas $90.9 \%$ (30/33) of TTV-positive patients required hospitalization $(\mathrm{OR}=2.81 ; 95 \% \mathrm{CI}$ $0.757-10.403)$. Intriguingly, all ARI patients with samples positive for TTV DNA were hospitalized (table 1). Of the 30 samples coinfected with TTV and a human respiratory virus, $96.7 \%$ (29/30) were taken from hospitalized patients $(\mathrm{OR}=58$; 95\% CI 2.56-1,313.926), and 27 were taken from patients with an initial diagnosis of ARI (OR = $18 ; 95 \%$ CI 1.234-262.67). Five of the 11 (45.5\%) samples infected with influenza A H3 were coinfected with TTV. Three of the 8 (37.5\%) samples infected with HMPV were coinfected with TTV. Twenty-one of the 42 (50\%) samples infected with HRV were coinfected with TTV. One HPIV-3-positive sample was also positive for TTV. Almost all hospitalized patients positive for TTV DNA were hospitalized for more than 3 days $(90 \%, 27 / 30)$ (tables 1 , 2). All samples were negative for $\mathrm{HGyV}$.

\section{Discussion}

Our study was conducted at a government-operated tertiary hospital that serves Surakarta and the surrounding area. One study revealed that Surakarta is the most densely populated city in Central Java and the eighth most densely populated city in Indonesia [12]. Surakarta has a tropical climate with a mean annual temperature of $30^{\circ}$ and a constantly high relative humidity $(>70 \%)$. It is lowland, flat terrain at $105 \mathrm{~m}$ above sea level. Surakarta is centrally located at the strategic paths connecting Semarang, Yogyakarta, and Surabaya, which is why Surakarta became an important business center for the surrounding district 
(http://www.surakarta.go.id/). Surakarta has 12 general hospitals; however, only the Dr. Moewardi General Hospital acts as a government-operated tertiary hospital in Surakarta.

Respiratory viruses were detected in $61.3 \%$ of patients, with the majority being from hospitalized patients. Few reports exist on the role of viral respiratory infections in respiratory disease in adults. RSV, HMPV, and influenza have been reported to correlate with a significant number of hospitalizations in adults aged $\geq 50$ years [21]. Picornaviruses have been reported as the most frequent virus causing infection among hospitalized adult patients with acute respiratory illness [22]. In the present study, HRV was detected most frequently, followed by the influenza A $\mathrm{H} 3$ virus, $\mathrm{HMPV}$, the influenza $\mathrm{B}$ virus, adenovirus, HCoV-OC43, and HPIV-3. Our samples were mostly derived from patients with ARI, suggesting that adults with ARI caused by a respiratory virus may be more likely to be hospitalized $[23,24]$.

With regard to the seasonal patterns of the viruses, the seasonal distribution of the different viruses was variable and remarkable. HRV was detected almost every month and peaked during the dry season and during the transition month from the dry season to the rainy season, whereas the influenza viruses, HMPV, adenovirus, HPIV-3, and $\mathrm{HCoV}-\mathrm{OC} 43$ were detected primarily during the transition month from the rainy season to the dry season.

HRV was detected frequently in adult patients presenting to the emergency department for respiratory distress and is associated with hospitalization, in line with our findings $[25,26]$. However, in ILI patients, we primarily detected HRV, followed by influenza A H3. This result is in contrast to a previous report from a tropical area $[27,28]$, in which the influenza virus was the most common virus detected in adult patients with ILI in Ecuador or Maracay, Venezuela. Although Ecuador is also a tropical country, it has a high altitude $(2,800 \mathrm{~m})$ with a cool, dry environment and therefore has environmental conditions different from those of Surakarta. Maracay is a city near the Caribbean coast with mountains on its north side and therefore also has environmental conditions different from those of Surakarta. Geographical and/or environmental conditions may affect the circulation patterns of respiratory viruses $[29,30]$.

Most patients with asthma exacerbation were positive for a respiratory virus, most often HRV, followed by the influenza A H3 virus, HMPV, and HPIV-3. Viral respiratory infections are already known as the most common cause of acute asthma exacerbation in both children and adults [31].
In this study, respiratory viruses were detected in $80 \%$ of patients with pneumonia, which is a higher rate than previously reported $[32,33]$. Moreover, all pneumonia patients infected with a respiratory virus were hospitalized. Pneumonia patients were most often infected with HRV, followed by influenza A H3, HMPV, and influenza $\mathrm{B}$. These results indicate that potential viral infections should be given more attention in adult pneumonia patients requiring hospitalization.

HRV was the most common viral agent detected in our study and was associated with ARI, hospitalization, asthma exacerbation, COPD exacerbation, and pneumonia. HRV A43 predominated, followed by B3, B6, B72, B14, A75, B37, A19, B92, and C. We hypothesize that all species of HRV detected in our study are also spread among other regions in Indonesia, especially Java Island. At present, these findings represent the first and only molecular data in GenBank for an HRV isolate from Indonesia.

Although the influenza B virus was detected in only one sample derived from a hospitalized patient with ARI and pneumonia, the influenza A H3N2 virus was the second most common viral agent detected in our study. Previous local studies have reported that influenza A H3N2 predominates in some sites in Indonesia [2,5], especially in ILI outpatients. At our study site, influenza A H3N2 was associated with ARI, hospitalization, asthma exacerbation, COPD exacerbation, and pneumonia. Based on our molecular analysis and comparisons with sequences from the GenBank/EMBL/DDBJ databases, the nucleotide sequences of all influenza A H3N2 isolates in our study shared a higher homology with foreign strains than with any influenza A H3N2 virus isolated previously in Indonesia. This result suggests that foreign influenza $\mathrm{A}$ H3N2 strains are occasionally introduced into Indonesia.

We reported the circulation and molecular data for HMPV in Indonesia for the first time, to the best of our knowledge. HMPV was detected only in samples taken from hospitalized patients with ARI and was associated with pneumonia, which is consistent with previous findings [34]. HMPV subtypes A1 and A2 were found circulating in Surakarta. We also reported for the first time the circulation and molecular data for human adenovirus B, HCoV-OC43, and HPIV-3 in Indonesia, all detected from hospitalized ARI patients.

TTV was detected in nasal brushing samples of children with recurrent or persistent pneumonia [35]. The TTV load was associated with airflow limitation within the peripheral airways in children with bronchiectasis or asthma $[36,37]$. TTV may disrupt the mucociliary escala-
Prasetyo et al. 
tor, similar to other respiratory viruses [35]; however, its pathological mechanism remains poorly understood. In the present study, the detection of TTV was associated with ARI and hospitalization and, intriguingly, all TTVpositive ARI patients were hospitalized. Single infections with TTV were not detected in nasal and throat samples from patients with exacerbations of asthma, COPD, and bronchiectasis. In addition, single infections with TTV were not detected in nasal and throat samples from patients with pneumonia. However, 8 pneumonia samples were positive for coinfection with TTV and a respiratory virus. We also found that coinfection with TTV and a human respiratory virus was associated with the incidence of ARI. Additional studies are warranted to further investigate the association of age with the contribution of TTV to viral respiratory diseases, especially when coinfected with a respiratory virus.

$\mathrm{HGyV}$, a novel virus resembling CAV, was detected in non-lesional skin specimens and in the blood of infected persons [16, 17]. HGyV could not be detected in bronchoalveolar lavage fluid samples, nasopharyngeal aspirates, or fecal samples from children [16]. However, CAV infects a wide range of cell types and has been associated with the worsening of pathologies caused by other viral and bacterial agents [38-40]. The absence of HGyV genomes in the respiratory specimens (nasal and throat swabs) derived from adults with ILI and ARI in the present study supports the idea that HGyV may not replicate in the cells of the respiratory tract and may not be associated with respiratory diseases.

To the best of our knowledge, this report is the first molecular epidemiology study in Indonesia of respiratory viruses (influenza A H3, influenza B, HMPV, HRV, adenovirus, HCoV-OC43, and HPIV-3), especially in adult patients with acute upper respiratory infections. Moreover, prior to this study, there were only limited data about the molecular epidemiology profiles of respi- ratory viruses in Indonesia, and none of the data were derived from adult patients with ARI. HMPV, HRV, adenovirus, HCoV-OC43, and HPIV-3 were also detected for the first time in Indonesia. However, our study had several limitations. We only tested for specific acute upper respiratory infection etiologies, including common human respiratory viruses and atypical bacteria; this limitation reflects a limited budget for etiological diagnosis, which is a common situation in hospitals in developing countries. The data collection was also limited to one tertiary hospital over a 1-year period due to the limited budget; therefore, the seasonal patterns for the viruses were derived from one season, and the number of study patients may have been insufficient to draw firm conclusions. Additional surveillance studies with larger sample sizes will be needed to confirm and extend our findings.

In our study, respiratory viruses were associated with ARI, asthma, pneumonia, and hospitalization, highlighting the necessity for further studies of respiratory viruses in adults. Routine testing for respiratory viruses may also be warranted for adults who have been hospitalized with ARI, especially when they develop asthma exacerbation or pneumonia. The phylogenetic analysis suggested that foreign influenza A H3N2 strains have been occasionally introduced into Indonesia. Also, the molecular data of influenza B virus, $\mathrm{HMPV}, \mathrm{HRV}$, adenovirus, $\mathrm{HCoV}$ OC43, and HPIV-3 isolated in Indonesia are reported for the first time in the present report.

\section{Acknowledgments}

This work was supported in part by grants from the Indonesian Directorate of Higher Education (No. 322/SP2H/PP/DP2M/ VI/2009 and No. 077/SP2H/PL/Dit.Litabmas/V/2013) and from APBN/DIPA UNS (No. 2342/UN27.16/PN/2012, 159a/UN27.11/ PN/2013, and No. 267a/UN27.16/PN/2013).

\section{References}

1 Prawira Y, Murniati D, Rusli A, Giriputro S, Setiawaty V, Oswari H, Said M: Clinical, laboratory, and radiologic characteristics of confirmed avian influenza (H5N1). Southeast Asian J Trop Med Public Health 2012;43:877889.

2 Kosasih H, Roselinda, Nurhayati, Klimov A, Xiyan X, Lindstrom S, Mahoney F, Beckett C, Burgess TH, Blair PJ, Uyeki TM, Sedyaningsih ER: Surveillance of influenza in Indonesia, 2003-2007. Influenza Other Respi Viruses 2013;7:312-320.
3 Dilantika C, Sedyaningsih E, Kasper M, Agtini M, Listiyaningsih E, Uyeki T, Burgess T, Blair P, Putnam S: Influenza virus infection among pediatric patients reporting diarrhea and influenza-like illness. BMC Infect Dis 2010;10:3.

4 Sedyaningsih E, Isfandari S, Setiawaty V, Rifati L, Harun S, Purba W, Imari S, Giriputra S, Blair P, Putnam S, Uyeki T, Soendoro T: Epidemiology of cases of $\mathrm{H} 5 \mathrm{~N} 1$ virus infection in Indonesia, July 2005-June 2006. J Infect Dis $2007 ; 196: 522-527$.
5 Beckett $\mathrm{C}$, Kosasih $\mathrm{H}, \mathrm{Ma}$ 'roef C, Listiyaningsih E, Elyazar I, Wuryadi S, Yuwono D, McArdle J, Corwin A, Porter K: Influenza surveillance in Indonesia: 1999-2003. Clin Infect Dis 2004;39:443-449.

- 6 Corwin A, Simanjuntak C, Ingkokusumo G, Sukri N, Larasati R, Subianto B, Muslim H, Burni E, Laras K, Putri M, Hayes C, Cox N: Impact of epidemic influenza A-like acute respiratory illness in a remote jungle highland population in Irian Jaya, Indonesia. Clin Infect Dis 1998;26:880-888.
Respiratory Viruses and TTV in Adults with ARI 
7 Simões E, Mutyara K, Soh S, Agustian D, Hibberd M, Kartasasmita C: The epidemiology of respiratory syncytial virus lower respiratory tract infections in children less than 5 years of age in Indonesia. Pediatr Infect Dis J 2011;30: 778-784.

8 Omer S, Sutanto A, Sarwo H, Linehan M, Djelantik I, Mercer D, Moniaga V, Moulton L, Widjaya A, Muljati P, Gessner B, Steinhoff M: Climatic, temporal, and geographic characteristics of respiratory syncytial virus disease in a tropical island population. Epidemiol Infect 2008; 136:1319-1327.

9 Robertson S, Roca A, Alonso P, Simoes E, Kartasasmita C, Olaleye D, Odaibo G, Collinson M, Venter M, Zhu Y, Wright P: Respiratory syncytial virus infection: denominatorbased studies in Indonesia, Mozambique, $\mathrm{Ni}$ geria and South Africa. Bull World Health Organ 2004;82:914-922.

10 Djelantik I, Gessner B, Soewignjo S, Steinhoff M, Sutanto A, Widjaya A, Linehan M, Moniaga $\mathrm{V}$, Ingerani: Incidence and clinical features of hospitalization because of respiratory syncytial virus lower respiratory illness among children less than two years of age in a rural Asian setting. Pediatr Infect Dis J 2003;22:150-157.

11 Lu Y, Tong J, Pei F, Yang Y, Xu D, Ji M, Xing C, Jia P, Xu C, Wang Y, Li G, Chai Z, Liu Y, Han J: Viral aetiology in adults with acute upper respiratory tract infection in Jinan, Northern China. Clin Dev Immunol 2013, DOI: $10.1155 / 2013 / 869521$.

12 Badan Pusat Statistik: Population Census 2010. Jakarta, BPS, 2010.

13 World Health Organization: WHO European Guidance for Influenza Surveillance in $\mathrm{Hu}-$ mans. Copenhagen, WHO Regional Office for Europe, 2009.

-14 Leung TF, To MY, Yeung AC, Wong YS, Wong GW, Chan PK: Multiplex molecular detection of respiratory pathogens in children with asthma exacerbation. Chest 2010;137:348-354.

- 15 Irshad M, Singh S, Irshad K, Agarwal SK, Joshi YK: Torque teno virus: its prevalence and isotypes in North India. World J Gastroenterol 2008;14:6044-6051.

-16 Sauvage V, Cheval J, Foulongne V, Gouilh M, Pariente K, Manuguerra J, Richardson J, Dereure O, Lecuit M, Burguiere A, Caro V, Eloit M: Identification of the first human gyrovirus, a virus related to chicken anemia virus. J Virol 2011;85:7948-7950.

17 Maggi F, Macera L, Focosi D, Vatteroni M, Boggi U, Antonelli G, Eloit M, Pistello M: Human gyrovirus DNA in human blood, Italy. Emerg Infect Dis 2012;18:956-959.

18 Tamura K, Peterson D, Peterson N, Stecher G, Nei M, Kumar S: MEGA5: molecular evolutionary genetics analysis using maximum likelihood, evolutionary distance, and maximum parsimony methods. Mol Biol Evol 2011;28:2731-2739.
19 Gardner M, Altman D: Statistics with Confidence. London, BMJ Publications, 1994.

20 Mandell LA, Wunderink RG, Anzueto A, Bartlett JG, Campbell GD, Dean NC, Dowell SF, File TM Jr, Musher DM, Niederman MS, Torres A, Whitney CG; Infectious Diseases Society of America; American Thoracic Society: Infectious Diseases Society of America/ American Thoracic Society consensus guidelines on the management of community-acquired pneumonia in adults. Clin Infect Dis 2007;44:S27-S72.

-21 Widmer K, Zhu Y, Williams JV, Griffin MR, Edwards KM, Talbot HK: Rates of hospitalizations for respiratory syncytial virus, human metapneumovirus, and influenza virus in older adults. J Infect Dis 2012;206:56-62.

-22 Atmar R, Piedra P, Patel S, Greenberg S, Couch R, Glezen W: Picornavirus, the most common respiratory virus causing infection among patients of all ages hospitalized with acute respiratory illness. J Clin Microbiol 2012;50:506-508

23 Feikin D, Njenga M, Bigogo G, Aura B, Aol G, Audi A, Jagero G, Muluare P, Gikunju S, Nderitu L, Balish A, Winchell J, Schneider E, Erdman D, Oberste M, Katz M, Breiman R: Etiology and Incidence of viral and bacterial acute respiratory illness among older children and adults in rural western Kenya, 20072010. PLoS One 2012;7:e43656.

24 Azziz-Baumgartner E, Alamgir AS, Rahman M, Homaira N, Sohel BM, Sharker MA, Zaman RU, Dee J, Gurley ES, Al Mamun A, Mah EMS, Fry AM, Widdowson MA, Bresee J, Lindstrom S, Azim T, Brooks A, Podder G, Hossain MJ, Luby SP: Incidence of influenza-like illness and severe acute respiratory infection during three influenza seasons in Bangladesh, 2008-2010. Bull World Health Organ 2012;90:12-19.

25 Pierangeli A, Scagnolari C, Selvaggi C, Verzaro S, Spina M, Bresciani E, Antonelli G, Bertazzoni G: Rhinovirus frequently detected in elderly adults attending an emergency department. J Med Virol 2011;83:2043-2047.

26 Fry A, Lu X, Olsen S, Chittaganpitch M, Sawatwong P, Chantra S, Baggett H, Erdman $D$ : Human rhinovirus infections in rural Thailand: epidemiological evidence for rhinovirus as both pathogen and bystander. PLoS One 2011;6:e17780.

27 Douce R, Aleman W, Chicaiza-Ayala W, Madrid C, Sovero M, Delgado F, Rodas M, Ampuero J, Chauca G, Perez J, Garcia J, Kochel T, Halsey E, Laguna-Torres V: Sentinel surveillance of influenza-like-illness in two cities of the tropical country of Ecuador: 2006-2010. PLoS One 2011;6:e22206.

28 Comach G, Teneza-Mora N, Kochel TJ, Espino C, Sierra G, Camacho DE, Laguna-Torres VA, Garcia J, Chauca G, Gamero ME, Sovero M, Bordones S, Villalobos I, Melchor A, Halsey ES: Sentinel surveillance of influenza-like illness in two hospitals in Maracay, Venezuela: 2006-2010. PLoS One 2012; e44511.
29 Hanley B, Borup B: Aerosol influenza transmission risk contours: a study of humid tropics versus winter temperate zone. Virol J 2010; 7:98.

30 Soebiyanto R, Adimi F, Kiang R: Modeling and predicting seasonal influenza transmission in warm regions using climatological parameters. PLoS One 2010;5:e9450.

31 Jackson D, Johnston S: The role of viruses in acute exacerbations of asthma. J Allergy Clin Immunol 2010;125:1178-1187.

32 Takahashi K, Suzuki M, le NM, Anh N, Huong L, Son T, Long P, Ai N, le HT, Morimoto K, Kilgore P, Anh D, Ariyoshi K, Yoshida L: The incidence and aetiology of hospitalised community-acquired pneumonia among Vietnamese adults: a prospective surveillance in Central Vietnam. BMC Infect Dis 2013;13: 296.

33 Luchsinger V, Ruiz M, Zunino E, Martinez MA, Machado C, Piedra PA, Fasce R, Ulloa MT, Fink MC, Lara P, Gebauer M, Chavez F, Avendano LF: Community-acquired pneumonia in Chile: the clinical relevance in the detection of viruses and atypical bacteria. Thorax 2013;68:1000-1006.

34 Johnstone J, Majumdar S, Fox J, Marrie T: Viral infection in adults hospitalized with community-acquired pneumonia: prevalence, pathogens, and presentation. Chest 2008;134: 1141-1148.

35 Pifferi M, Maggi F, Cristofano CD, Cangiotti A, Nelli L, Bevilacqua G, Macchia P, Bendinelli $\mathrm{M}$, Boner A: Torquetenovirus infection and ciliary dysmotility in children with recurrent pneumonia. Pediatr Infect Dis J 2008;27: 413-418.

36 Pifferi M, Maggi F, Caramella D, Marco ED, Andreoli E, Meschi S, Macchia P, Bendinelli $\mathrm{M}$, Boner A: High torquetenovirus loads are correlated with bronchiectasis and peripheral airflow limitation in children. Pediatr Infect Dis J 2006;25:804-808

37 Pifferi M, Maggi F, Andreoli E, Lanini L, Marco E, Fornai C, Vatteroni M, Pistello M, Ragazzo V, Macchia P, Boner A, Bendinelli M: Associations between nasal torquetenovirus load and spirometric indices in children with asthma. J Infect Dis 2005;192:11411148.

38 Haridy M, Goryo M, Sasaki J, Okada K: Pathological and immunohistochemical study of chickens with co-infection of Marek's disease virus and chicken anaemia virus. Avian Pathol 2009;38:469-483.

- 39 Toro H, van Santen VL, Hoerr F, Breedlove C: Effects of chicken anemia virus and infectious bursal disease virus in commercial chickens. Avian Dis 2009;53:94-102.

40 Schat K: Chicken anemia virus. Curr Top Microbiol Immunol 2009;331:151-183. 